\title{
QUANTIFICATION OF PUPIL PARAMETERS IN DISEASED AND NORMAL EYES WITH NEAR INFRARED IRIS TRANSILLUMINATION IMAGING
}
1,4,5 Daniel K. Roberts, O.D., Ph.D., 2,3Yongyi Yang, Ph.D., ${ }^{2,3,4}$ Ana S. Lukic, Ph.D., ${ }^{4}$ Jacob T. Wilensky, M.D., ${ }^{2,3}$ Miles N. Wernick, Ph.D.

${ }^{1}$ Illinois Eye Institute, Illinois College of Optometry, Department of Clinical Education, Chicago, IL

${ }^{2}$ Illinois Institute of Technology, Department of Electrical and Computer Engineering, Chicago, IL

${ }^{3}$ Predictek, Inc., Chicago, IL

${ }^{4}$ Uni versity of Illinois at Chicago, School of Medicine, Department of Ophthalmology and Visual Sciences, Chicago, IL

${ }^{5}$ University of Illinois at Chicago, School of Public Health, Division of Epidemiology and Biostatistics, Chicago, IL

Submitted to: Ophthalmic Lasers, Surgery, and Imaging - Revision 2 - 1.11.12

Word count: 2,625

Figures: 8

Tables: 3

Grant Support

NEIEY015604 (AL, YY, MNW).

Disclosures

MNW is President of Predictek, Inc., a company that has been recipient of an $\mathrm{NIH} / \mathrm{NEI}$ SBIR grant (EY015604) and development of infrared technology for ophthalmic examination. AL and $Y Y$ are employees of Predictek, and DKR and JTW have consultant roles on grant EY015604. DKR, MNW, AL, and YY have potential financial interests as patent holders related to infrared imaging technology.

Presented in part at the Annual Meeting of the Association for Research in Vision and Ophthalmology, Ft. Lauderdale, FL, May, 2010. 


\section{Abstract}

Purpose: To investigate near infrared iris transillumination (NIRit) imaging as a new method to quantify pupil shape, size, and position because the imaging modality can uniquely provide simultaneous information regarding iris structural details that influence pupil characteristics and because exploration of related techniques could promote discovery helpful to clinical research and care. Methods: Digital NIRit images of normal and diseased eyes were used along with computer-assisted techniques to quantify four primary pupil parameters, including pupil roundness $(P R)$, pupil ovalness $(P O)$, pupil size (PS), and pupil eccentricity $(P E)$. A combined measure of $P R$ and $P O$ was also developed, i.e., the pupil circularity index $(P C l)$. Repeatability of the measures was studied and example analyses were performed. Results: Pupil measures could be calculated for right eyes of 307 subjects ( 164 normal, 143 other), with $<0.5 \%$ exclusions due to image quality. Repeatability study did not show significant bias $(P<0.05)$ for any of the four primary measures. Example analyses could show age associated differences in pupil shape $(\geq 50$ year-olds had less regular pupils than $<50$-year-olds: median $P C l=0.009$ vs $0.006 ; \mathrm{P}<0.01$ ), and that a group of pigment dispersion syndrome subjects $(\mathrm{N}=27)$ had less regular pupils than a group of matched controls $(P O=0.9966$ vs. 0.9990; $\mathrm{P}<0.05)$. Conclusions: Digital NIRit imaging can provide novel, reliable, and informative methods to quantify pupil characteristics while providing simultaneous information about iris structure that may influence these parameters. 


\section{Introduction}

Infrared techniques have been widely used to assess the pupil, with most attention being given to pupil motion and reactivity in relation to a variety of applications. ${ }^{(1-13)}$ A common feature of these methods has been direct illumination of the front of the eye with a light source along with photographic capture of reflected light with a near infrared-sensitive camera system. Although these techniques are useful and have their roles, they do not provide simultaneous transillumination information about iris structural detail, which could be useful in providing etiologic information about tissue factors directly affecting pupil shape, position, and function (Figure 1).

Near infrared iris transillumination (NIRit) imaging provides a sensitive means to detect and record structural details of the iris, and example conditions for which NIRit imaging may provide useful information include pigment dispersion syndrome (PDS), iridociliary cysts, Fuchs' heterochromic iridocyclitis, diabetic iridopathy, traumatic iridopathy, and pseudophakic and phakic IOL complications. ${ }^{(14-21)}$ Recently, we learned that NIRit imaging could be adapted for clinical quantification of pupil parameters and that it may be useful for certain clinical investigation. For example, although the literature suggests the presence of pupil abnormalities in people with PDS, ${ }^{(22-24)}$ which may be caused by muscle tissue degeneration, ${ }^{(25 ; 26)}$ pupil alteration in PDS has not been formally tested using objective methods. In the following report, we show how NIRit imaging may be adapted for clinical quantification of pupil size, shape, and position parameters and used for clinical study of diseased and normal eyes. Knowledge of these methods may help promote clinical discovery and help identify new applications. 


\section{Methods}

For the analyses, we used a NIRit database consisting of images collected over a several year period within an inner-city, eye care teaching facility in Chicago, Illinois, USA. All subjects were imaged in conjunction with prior studies aimed to explore NIRit imaging. The clinic population from which the database was derived was about $75 \%$ African-American, which is reflected in the database composition. The total NIRit database did not precisely mirror the institution's population from which it was obtained nor the full spectrum of diseases that might affect iris translucency and/or pupil features. Included in analyses were 307 people (203 females, $66.1 \%$ ) with a mean age \pm $\mathrm{SD}=50.9 \pm 17.4$ years $($ range $=11-94$ years $)$. There were $213(69.4 \%)$ AfricanAmericans, 75 (24.4\%) Whites, 10 (3.3\%) Hispanics, and 9 (2.9\%) with other descent. Only right eyes were used for analyses, and 164 (53.4\%) had normal eye health, 54 $(17.6 \%)$ had the long anterior zonule trait with pigment dispersion signs, ${ }^{(21 ; 27)} 35$ $(11.4 \%)$ had classic or suspected classic pigment dispersion syndrome, $11(3.6 \%)$ were pseudophakic, $7(2.3 \%)$ had angle recession or a history of eye trauma, and $7(2.3 \%)$ had unexplained pigment dusting of the cornea or lens. Some of the 307 eyes also had diabetic iridopathy, Axenfeld-Rieger anomaly, Posner-Schlossman syndrome, and pseudoexfoliation syndrome. Several subjects had albinism, ocular hypertension or primary open-angle glaucoma, and a few had retinal diagnoses only, including idiopathic choroidal folds, myopic degeneration, and retinal pigment epithelial detachment. There were occasional subjects with more than one condition in the same eye. Subjects had comprehensive eye exams, with work-up including ocular/medical 
history, extraocular muscle testing, confrontation visual fields, pupil testing, subjective refraction, slit lamp exam, Goldmann tonometry, gonioscopy, and dilated fundus exam.

Excluded from a total dataset of 336 subjects were 29 who had missing information, image blurring, poor eye centration, and/or excessive eyelid coverage. Among exclusions were 11 normals, 4 with long anterior zonules ${ }^{(21 ; 27)}, 4$ pseuodophakes, and 2 with albinism. Subjects were not excluded due to a particular diagnosis. Among the 29 exclusions were 18 African-Americans and 11 with unknown or other race.

Subjects were imaged by a single examiner (DKR) using a technique previously described. ${ }^{(28)}$ The basic method used a modified digital camera with its infrared filter removed (COOLPIX 950, Nikon Corp, Tokyo, Japan) to photograph the iris while it was illuminated with visible and infrared light via a standard ophthalmic transilluminator (HEINE USA Ltd., Dover, NH) while it was directed perpendicular to the globe against the inferior eyelid. The camera was mounted to a 13-in, expandable tabletop tripod positioned several inches from a chin/headrest apparatus used for patient stability. The camera's "macro close-up" mode was used to produce magnification and its flash was turned off. To maximize iris surface area, consensual pupil constriction in the eye being photographed was promoted by having the subject fixate on a second, focal light source at near, which prevented light scatter toward the opposite eye. Overhead room illumination was also turned off to prevent extraneous light from reducing the quality of the NIRit images.

Pupil contour lines were created using an automated computer algorithm that relied on brightness change cues at the pupil border (Figure 2). Two measures of pupil 
shape were calculated, including a pupil roundness measure $(P R=\{2|\mathrm{P} \cap \mathrm{C}| /[|\mathrm{P}|+|\mathrm{C}|]\}=$ Dice similarity coefficient between the outlined pupil and a reference perfect disk cocentric and equal area with the pupil; range $=0-1$; perfect circle $=1$ ) and a pupil ovalness measure $(P O=\{2|\mathrm{P} \cap \mathrm{E}| /[|\mathrm{P}|+|\mathrm{E}|]\}=$ Dice similarity coefficient between the outlined pupil and a reference perfect ellipse co-centric and equal area with the pupil; range $=0-1$; perfect ellipse=1) (Figure 2). For the $P R$ and $P O$ measures, the Dice coefficient could be interpreted as twice the area in common with the perfect circle (or ellipse) and pupil area divided by the sum of their individual areas. A value $=0$ would indicate no overlap, and a value $=1$ would indicate perfect overlap. In comparing no rmal and irregular pupils, there would be an expectation of skewed values near 1 , especially with subtle dyscoria. In addition, we also calculated pupil eccentricity $(P E)$ and relative pupil size $(P S)$ (Figure 3). These measures relied on the automated pupil contour line, and to generate an automated outline of the outer iris border, they also required manual selection of four reference points denoting the outer extent of visible iris at the 12, 3, 6, and 9 o'clock positions. For $P E$, the full iris center of gravity (average coordinate location) was automatically calculated and compared to the pupil center of gravity. PE represented the distance between the two centers as a percentage of the total iris diameter, and $P S$ represented the pupil area as a percentage of the summed iris area and pupil areas.

In addition to the $P R, P O, P E$, and $P S$ measures, $P R$ and $P O$ were used together to calculate the pupil circularity index measure $(P C l)$. This was computed as the geometric distance, i.e., $P C I=\sqrt{ }\left\{(1-P R)^{2}+(1-P O)^{2}\right\}$, between any point formed by " $P R$, PO" and the position "1,1" (Figure 4). 
Analyses were performed using the SAS ${ }^{\circledR}$ System, Release 9.2 for Microsoft Windows ${ }^{\circledR}$ (SAS Institute Inc., Cary, NC). Student's $t$ test and/or the Wilcoxon rank-sum test were used for simple group comparisons, and multiple logistic regression was used to examine multiple variables simultaneously. Assumptions were met for analyses. Institutional Review Board approval was obtained for the investigation.

\section{Results}

A summary of all normal and diseased right eye measures is shown in Table 1, and Figure 5 illustrates example eyes along the spectrum of $P R$ and $P O$ measures. Histograms showing distributions of the normal right eyes are shown in Figures 6 and 7 . Whereas the $P R, P O, P C l$, and $P E$ measures are skewed, $P S$ shows a more Gaussian distribution. As anticipated, a plot of $P R$ against $P O$ in Figure 6 shows clustering of points in the graph's upper right corner where values approach 1.0. However, the graph illustrates that varying degree of circularity existed and that differentiation is possible between pupils that are "not perfectly round but still highly elliptical" and pupils that are "not perfectly round and not perfectly elliptical." By definition, if a pupil is perfectly round, it must be perfectly elliptical. Thus, plotted points occur above a diagonal plane.

As shown in Table 1, normal eyes tend to have higher mean/median $P R$ and $P O$ values and lower $P C /$ values than "other" eye values, which is consistent with pupils that tend to be more round. Normal eyes also tend to have lower mean/median PE values than "other" eyes, indicating less displacement between the iris and pupil centers. Ranges are also broader for "other" eyes than normal eyes. 
Scatter plots of normal eyes in Figure 7 show how $P S$ and $P E$ may be compared against the $\mathrm{PC} /$ measure, with least square regression lines suggesting there could be an inverse correlation of pupil circularity with pupil size and a positive correlation of pupil circularity with pupil eccentricity. This demonstrates potential value of the pupil size measure, which would allow for "adjustment" of pupil size in statistical analyses.

To test repeatability of the pupil measures, in case pupil brightness or other variation might affect the nature of the automated pupil outline, a $10 \%$ random sample was selected of normal and disease eyes. Separate right eye images, obtained on the same occasion, from these subjects were then reassessed in the same manner as before. There was no significant bias $(P>0.05)$ between the first and second measurements for any of the four pupil measures (mean bias+SD: $P R=0.006 \pm 0.0023$; $P O=0.0001 \pm 0.0011 ; P S=-0.0078 \pm 0.0324 ; P E=0.0029 \pm 0.0115)$. In addition, difference vs. means plots showed normal distributions, and there was no suggestion of measurement level dependent bias. ${ }^{(29)}$

Although there were many possible analyses, to illustrate how this quantification system could be used, we selected out $A$ frican-Americans $(N=111$; median age $=49$ years; 72 females, 39 males) with normal eyes to explore pupil measures in two age groups, i.e., $<50$ years $(N=49)$ vs. $\geq 50$ years $(N=62)$ (Table 2$)$. Here, mean pupil size of the younger group was significantly larger than the older group ( $P S=0.33$ vs. 0.28 , $\mathrm{P}<0.001$ ), and multiple logistic regression showed that while controlling for pupil size, all three of the pupil shape measures $(P R, P O, P C l)$ were likely associated $(P<0.01)$ with older age when each was assessed individually. Thus, the analysis showed that the people $\geq 50$ years may on average have less regular pupils than people $<50$ years. 
Neither gender nor the PE measure was associated with age group, and controlling for gender along with pupil size did not change the conclusions.

To further illustrate how the quantification methods could be useful, we performed a comparative analysis of available right eye images of classic PDS subjects ( $N=27 ; 13$ White, 12 African-American, 2 Hispanic; 16 females) and an equal number of normal controls who were frequency-matched on age (5-year intervals), race, gender, and eye color (brown, hazel, blue). The mean age (range) was 45.1+13.0 years (25-67 years) for PDS subjects and 44.9+14.5 years (23-68 years) for controls. Plot of the $P R$ and $P O$ measures showed separation of certain PDS eyes from most other eyes (Figure 8), and a ranking of PO measures showed that eight of ten ( $80 \%)$ subjects with the lowest $P O$ scores had PDS (Table 3). Median $P O$ values reflected this, even with a low number of subjects, being marginally lower for PDS eyes than for normal eyes $(P O=0.9966$ vs. $0.9990, P=0.025) . P R$ values $(P R=0.9925$ vs $0.9924, P=0.45)$ and other measures ( $P C l, P E$, and $P S)$ were similar.

\section{Discussion}

To quantify pupil shape, we used two measures, i.e., pupil roundness $(P R)$ and pupil ovalness $(P O)$, which could be assessed separately or combined into a single index of pupil regularity, i.e., the pupil circularity index $(P C l)$ measure. The utility of two separate measures was supported by showing that both normal and diseased eyes could be elliptical but not circular. Having the separate and combined measures provides versatility and has the potential to obtain more specific information about pupil status in case certain conditions cause pupils that are highly elliptical but not round, 
while other condition may cause pupils that are neither round nor elliptical. An ellipse also contains a "major axis" and a "minor axis," whereby orientation could be dependent on iris structural changes made visible by the nature of the NIRit method.

To appreciate the general location of the $P R$ and $P O$ measures on a scatter plot, it is helpful to consider the relationship between a circle and an ellipse. An ellipse is a curved line that forms a closed loop with the characteristic of having two foci where the sum of the distances from the foci to any point on the curved line has a constant value. A circle is a special case of an ellipse whereby both foci are at the center of the closed loop. Since a perfect circle is also a perfect ellipse, if $P R=1.0$ then $P O=1.0$. It will also always be true that $P R \leq P O$, which causes all points to plot above a graph diagonal (Figure 4).

Although the pupil shape measures were derived using automated computer methods, the $P S$ and $P E$ measures require subjective input to mark reference points denoting the outer edges of the visible iris. Despite this step, the $P S$ and $P E$ measures were repeatable. The need for the observer input stemmed from image blurring at the limbal junction, which could prevent automated outlining of the outer iris border. Improved photographic methods might eliminate need for subjective inp ut altogether.

Due to the nature of the photographic methods, it would not be logical to use the pupil size measure for certain purposes such as assessing degree of anisocoria. The $P S$ measure is valuable though because it allows for statistical control of $P S$ when other measures vary as a function of pupil size. This was exemplified with the plot in Figure 7, which showed a potential relationship between $P C l$ and the $P S$ measure. 
It was not our intent here to conduct exhaustive study of potential relationships among the measures described, nor to suggest that the precise methods will be ideal for all circumstances. Rather, the goal is to introduce the fundamental concept of NIRit imaging in the assessment of pupil parameters because it might be useful in attempts to characterize the pupil characteristic trends of certain diseased and normal subgroups, such as the pupil distortion that may occur in people with PDS. The example analyses that we used to illustrate the overall pupil assessment method will require further study with larger sample sizes and greater subject diversity to validate and generalize these initial findings. Although our current analyses are limited to static photographs of the iris and pupil, dynamic relationships between the pupil and iris structure may also deserve future study, possibly with the aid of multiple still images with varying pupil size or with infrared videography techniques.

\section{Conclusions}

Digital NIRit imaging can provide novel, reliable, and informative methods to quantify pupil characteristics while providing simultaneous information about iris structure that may influence these parameters. 


\section{References}

(1) Fan X, Miles JH, Takahashi N, Yao G. Sex-specific lateralization of contraction anisocoria in transient pupillary light reflex. Invest Ophthalmol Vis Sci 2009; 50(3):1137-1144.

(2) Miki A, lijima A, Takagi M, Yaoeda K, Usui T, Hasegawa S et al. Pupillography of automated swinging flashlight test in amblyopia. Clin Ophthalmol 2008; 2(4):781786.

(3) Wilhelm H, Wilhelm B. Clinical applications of pupillography. J Neuroophthalmol 2003; 23(1):42-49.

(4) Morad Y, Lemberg H, Yofe N, Dagan Y. Pupillography as an objective indicator of fatigue. Curr Eye Res 2000; 21(1):535-542.

(5) Wilhelm $\mathrm{H}$. Neuro-ophthalmology of pupillary function--practical guidelines. J Neurol 1998; 245(9):573-583.

(6) Kawasaki A. Physiology, assessment, and disorders of the pupil. Curr Opin Ophthalmol 1999; 10(6):394-400.

(7) Bertinotti L, Pietrini U, Del RA, Casale R, Colangelo N, Zoppi M et al. The use of pupillometry in joint and connective tissue diseases. Ann N Y Acad Sci 2002; 966:446-455.

(8) Yan S, Tu Z, Lu W, Zhang Q, He J, Li Z et al. Clinical utility of an automated pupillometer for assessing and monitoring recipients of liver transplantation. Liver Transpl 2009; 15(12):1718-1727.

(9) Marx-Gross S, Krummenauer F, Dick HB, Pfeiffer N. Brimonidine versus dapiprazole: Influence on pupil size at various illumination levels. J Cataract Refract Surg 2005; 31(7):1372-1376.

(10) Maddess T, Bedford SM, Goh XL, James AC. Multifocal pupillographic visual field testing in glaucoma. Clin Experiment Ophthalmol 2009; 37(7):678-686.

(11) Lee JC, Kim JE, Park KM, Khang G. Evaluation of the methods for pupil size estimation: on the perspective of autonomic activity. Conf Proc IEEE Eng Med Biol Soc 2004; 2:1501-1504.

(12) Lundstrom L, Unsbo P. Transformation of Zernike coefficients: scaled, translated, and rotated wavefronts with circular and elliptical pupils. J Opt Soc Am A Opt Image Sci Vis 2007; 24(3):569-577. 
(13) Lowenstein O, Loenwenfeld IE. Electronic pupillography; a new instrument and some clinical applications. AMA Arch Ophthalmol 1958; 59(3):352-363.

(14) Alward WL, Munden PM, Verdick RE, Perell HR, Thompson HS. Use of infrared videography to detect and record iris transillumination defects. Arch Ophthalmol 1990; 108(5):748-750.

(15) Roberts DK, Chaglasian MA, Meetz RE. Iris transillumination defects in the pigment dispersion syndrome as detected with infrared videography: a comparison between a group of blacks and a group of nonblacks. Optom Vis Sci 1999; 76(8):544-549.

(16) Roberts DK. Digital infrared photography assists in the detection of iris and ciliary body cysts. J Glaucoma 2003; 12(3):288-291.

(17) Roberts DK, Wernick MN. Infrared imaging technique may help demonstrate iris transillumination defects in blacks who show other pigment dispersion syndrome clinical signs. J Glaucoma 2007; 16(5):440-447.

(18) Saari M, Vuorre I, Nieminen $\mathrm{H}$. Infrared transillumination stereophotography of normal iris. Can J Ophthalmol 1977; 12(4):308-311.

(19) Saari M, Vuorre I, Nieminen H. Infra-red transillumination stereophotography of the iris in Fuchs's heterochromic cyclitis. Br J Ophthalmol 1978; 62(2):110-115.

(20) Haynes WL, Alward WL, McKinney JK, Munden PM, Verdick RE. Quantitation of Iris Transillumination Defects in Eyes of Patients with Pigmentary Glaucoma. J Glaucoma 1994; 3(2):106-113.

(21) Roberts DK, Lukic AS, Yang Y, Moroi SE, Wilensky JT, Wernick MN. Novel observations and potential applications using digital infrared iris imaging. Ophthalmic Surg Lasers Imaging 2009; 40(2):207-216.

(22) Feibel RM, Perlmutter JC. Anisocoria in the pigmentary dispersion syndrome. Am J Ophthalmol 1990; 110(6):657-660.

(23) Haynes WL, Thompson HS, Kardon RH, Alward WL. Asymmetric pigmentary dispersion syndrome mimicking Horner's syndrome. Am J Ophthalmol 1991; 112(4):463-464.

(24) Krebs DB, Colquhoun J, Ritch R, Liebmann JM. Asymmetric pigment dispersion syndrome in a patient with unilateral Horner's syndrome. Am J Ophthalmol 1989; 108(6):737-738.

(25) Fine BS, Yanoff M, Scheie HG. Pigmentary "glaucoma". A histologic study. Trans Am Acad Ophthalmol Otolaryngol 1974; 78(2):OP314-OP325. 
(26) Kampik A, Green WR, Quigley HA, Pierce LH. Scanning and transmission electron microscopic studies of two cases of pigment dispersion syndrome. Am J Ophthalmol 1981; 91(5):573-587.

(27) Moroi SE, Lark KK, Sieving PA, Nouri-Mahdavi K, Schlotzer-Schrehardt U, Katz GJ et al. Long anterior zonules and pigment dispersion. Am J Ophthalmol 2003; 136(6):1176-1178.

(28) Chan EC, Roberts DK, Loconte DD, Wernick MN. Digital camera system to perform infrared photography of iris transillumination. J Glaucoma 2002; 11(5):426-428.

(29) Altman D. Measurement in medicine: the analysis of method comparison studies. Statistician, 307-17. 1983. 
Table 1

Pupil measures for normal right eyes $(\mathrm{N}=164)$ and "other" right eyes $(\mathrm{N}=143)$

\begin{tabular}{|c|c|c|c|c|c|}
\hline $\begin{array}{c}\text { Pupil } \\
\text { Measurement }\end{array}$ & Mean & Median & Range & $\begin{array}{l}\text { Standard } \\
\text { Deviation }\end{array}$ & $\begin{array}{c}5^{\mathrm{tn}}, 95^{\mathrm{tn}} \\
\text { percentiles } \\
\text { Normal Eyes }\end{array}$ \\
\hline $\begin{array}{l}\text { Pupil Roundness } \\
\qquad(P R)\end{array}$ & $\begin{array}{c}0.992 \\
+(0.984)\end{array}$ & $\begin{array}{c}0.994 \\
(0.991)\end{array}$ & $\begin{array}{c}0.996-1.0 \\
(0.768-1.0)\end{array}$ & $\begin{array}{c}0.006 \\
(0.027)\end{array}$ & $0.978,0.999$ \\
\hline $\begin{array}{l}\text { Pupil Ovalness } \\
(P O)\end{array}$ & $\begin{array}{c}0.998 \\
(0.994)\end{array}$ & $\begin{array}{c}0.998 \\
(0.997)\end{array}$ & $\begin{array}{c}0.988-1.0 \\
(0.897-1.0)\end{array}$ & $\begin{array}{c}0.003 \\
(0.110)\end{array}$ & $0.992,1.0$ \\
\hline $\begin{array}{l}\text { Pupil Size } \\
\text { (PS) }\end{array}$ & $\begin{array}{c}0.300 \\
(0.288)\end{array}$ & $\begin{array}{c}0.298 \\
(0.278)\end{array}$ & $\begin{array}{c}0.129-0.483 \\
(0.177-0.569)\end{array}$ & $\begin{array}{c}0.076 \\
(0.064)\end{array}$ & $0.191,0.443$ \\
\hline $\begin{array}{l}\text { Pupil Eccentricity } \\
(P E)\end{array}$ & $\begin{array}{c}0.022 \\
(0.027)\end{array}$ & $\begin{array}{c}0.021 \\
(0.024)\end{array}$ & $\begin{array}{c}0.001-0.065 \\
(0.003-0.211)\end{array}$ & $\begin{array}{c}0.011 \\
(0.064)\end{array}$ & $0.007,0.040$ \\
\hline $\begin{array}{l}\text { Pupil Circularity Index } \\
\text { (PCI) }\end{array}$ & $\begin{array}{l}0.009 \\
(0.017)\end{array}$ & $\begin{array}{c}0.007 \\
(0.011)\end{array}$ & $\begin{array}{c}0.000-0.035 \\
(0.000-0.254)\end{array}$ & $\begin{array}{c}0.006 \\
(0.029)\end{array}$ & $0.001,0.022$ \\
\hline
\end{tabular}

\footnotetext{
T"Other" eye measure s listed in parentheses.
} 
Table 2

$\underline{\text { Right eye pupil measures for African-American normals, age }<50 \text { vs. }>=50 \text { years }}$

\begin{tabular}{|c|c|c|c|c|c|}
\hline $\begin{array}{c}\text { Pupil } \\
\text { Measurement }\end{array}$ & Mean & Median & Range & $\begin{array}{l}\text { Standard } \\
\text { Deviation }\end{array}$ & $\begin{array}{c}\text { Unadjusted } \\
\text { P-value }\end{array}$ \\
\hline $\begin{array}{l}\text { Pupil Roundness } \\
(P R)\end{array}$ & $\begin{array}{c}0.993 \\
{ }^{\dagger}(0.990)\end{array}$ & $\begin{array}{l}0.995 \\
(0.992)\end{array}$ & $\begin{array}{l}0.984-1.0 \\
(0.966-1.0)\end{array}$ & $\begin{array}{c}0.004 \\
(0.007)\end{array}$ & 0.02 \\
\hline $\begin{array}{l}\text { Pupil Ovalness } \\
\qquad(P O)\end{array}$ & $\begin{array}{l}0.998 \\
(0.997)\end{array}$ & $\begin{array}{c}0.999 \\
(0.998)\end{array}$ & $\begin{array}{c}0.990-1.0 \\
(0.993-1.0)\end{array}$ & $\begin{array}{c}0.002 \\
(0.003)\end{array}$ & 0.05 \\
\hline $\begin{array}{l}\text { Pupil Size } \\
\qquad(P S)\end{array}$ & $\begin{array}{l}0.326 \\
(0.279)\end{array}$ & $\begin{array}{l}0.319 \\
(0.273)\end{array}$ & $\begin{array}{c}0.168-0.477 \\
(0.135-0.458)\end{array}$ & $\begin{array}{l}0.074 \\
(0.070)\end{array}$ & $<0.001$ \\
\hline $\begin{array}{l}\text { Pupil Eccentricity } \\
(P E)\end{array}$ & $\begin{array}{c}0.022 \\
(0.021)\end{array}$ & $\begin{array}{c}0.021 \\
(0.020)\end{array}$ & $\begin{array}{c}0.005-.045 \\
(0.001-0.065)\end{array}$ & $\begin{array}{c}0.011 \\
(0.012)\end{array}$ & 0.76 \\
\hline $\begin{array}{l}\text { Pupil Circularity Index } \\
\text { (PCI) }\end{array}$ & $\begin{array}{c}0.007 \\
(0.010)\end{array}$ & $\begin{array}{l}0.006 \\
(0.009)\end{array}$ & $\begin{array}{c}0.000-0.018 \\
(0.000-0.035)\end{array}$ & $\begin{array}{c}0.005 \\
(0.007)\end{array}$ & 0.008 \\
\hline
\end{tabular}

'>=50-year-old subjects' measure s listed in parenthese s. 


\section{Table 3}

Subject ranking by lowest $P S$ values in matched study of classic PDS right eyes and normal subject right eyes ( $N=27$ per group)

\begin{tabular}{ccccccccc} 
Subject ID & Diagnosis & Age & Race & Gender & $\begin{array}{c}\text { Iris } \\
\text { Color }\end{array}$ & PR & $P O$ & $\begin{array}{c}P O \\
\text { Rank }\end{array}$ \\
\hline 161 & aPDS & 56 & W & M & BLUE & 0.9686 & 0.9777 & 1 \\
70 & PDS & 57 & W & M & BROWN & 0.9655 & 0.9876 & 2 \\
116 & PDS & 65 & AA & F & BROWN & 0.9770 & 0.9881 & 3 \\
17 & PDS & 35 & H & F & BROWN & 0.9895 & 0.9920 & 4 \\
99 & PDS & 49 & W & M & BLUE & 0.9719 & 0.9928 & 5 \\
188 & NORMAL & 51 & W & F & HAZEL & 0.9909 & 0.9929 & 6 \\
147 & PDS & 51 & W & M & BLUE & 0.9910 & 0.9933 & 7 \\
306 & PDS & 34 & AA & F & BROWN & 0.9925 & 0.9935 & 8 \\
268 & NORMAL & 54 & AA & F & BROWN & 0.9921 & 0.9939 & 9 \\
343 & PDS & 39 & W & F & BROWN & 0.9928 & 0.9941 & 10 \\
$\ldots$ & & & & & & & & \\
$\ldots$ & & & & & & & & \\
35 & NORMAL & 40 & W & M & BLUE & 0.9848 & 1.0000 & 54
\end{tabular}

${ }^{a}$ Abbreviations: AA, African-American; F, female; H, Hispanic; M, male; PDS, pigment dispersion syndrome; PR, pupil roundness; PO, pupil ovalness; W, white. 


\section{Figure Legends}

Fig. 1. Subject with proliferative diabetic retinopathy and unexplained dyscoria has region of reduced light transmittance in meridian of pupil elongation.

Fig. 2. Computer-generated pupil outline and marked center of gravity (left). Schematics that illustrate methods to quantify pupil roundness $(P R)$ and pupil ovalness $(P O)$ (right). Fitted regions represent a perfect circle or ellipse with same area as pupil area, with centers of gravity aligned.

Fig. 3. Pupil eccentricity $(P E)$ represents the distance between the pupil area's center of gravity and full iris center of gravity (left), calculated as a percentage of the full iris diameter. PS is the pupil area as a percentage of the summed iris and pupil area (right) ( $\mathrm{P}=$ pupil area, I=Iris area).

Fig. 4. Pupil circularity index $(P C l)$ was computed as the distance (dotted lines on scatter plot), i.e., $P C l=\sqrt{ }\left\{(1-P R)^{2}+(1-P O)^{2}\right\}$ between any point formed by $(P R$, $P O)$ from $(1,1)$. The relationship between a circle and an ellipse is also shown to help explain why a plot of $P R$ and $P O$ measures will not have any points below a diagonal line on the graph.

Fig. 5. Example eyes and corresponding $P R, P O$, and $P C /$ measures.

Fig. 6. Histograms of pupil shape measures for normal right eyes and a scatter plot of pupil roundness $(P R)$ against pupil ovalness $(P O)$ for normal right eyes.

Fig. 7. Histograms showing pupil size $(P S)$ and pupil eccentricity $(P E)$ distributions for normal right eyes and scatter plots of $P S$ and $P E$ against the pupil circularity index $(P C /)$ measure for normal right eyes.

Fig. 8. Scatter plot of $P R$ and $P O$ pupil shape measures for 27 classic PDS right eyes and 27 normal subject right eyes matched on age, race, and gender. 


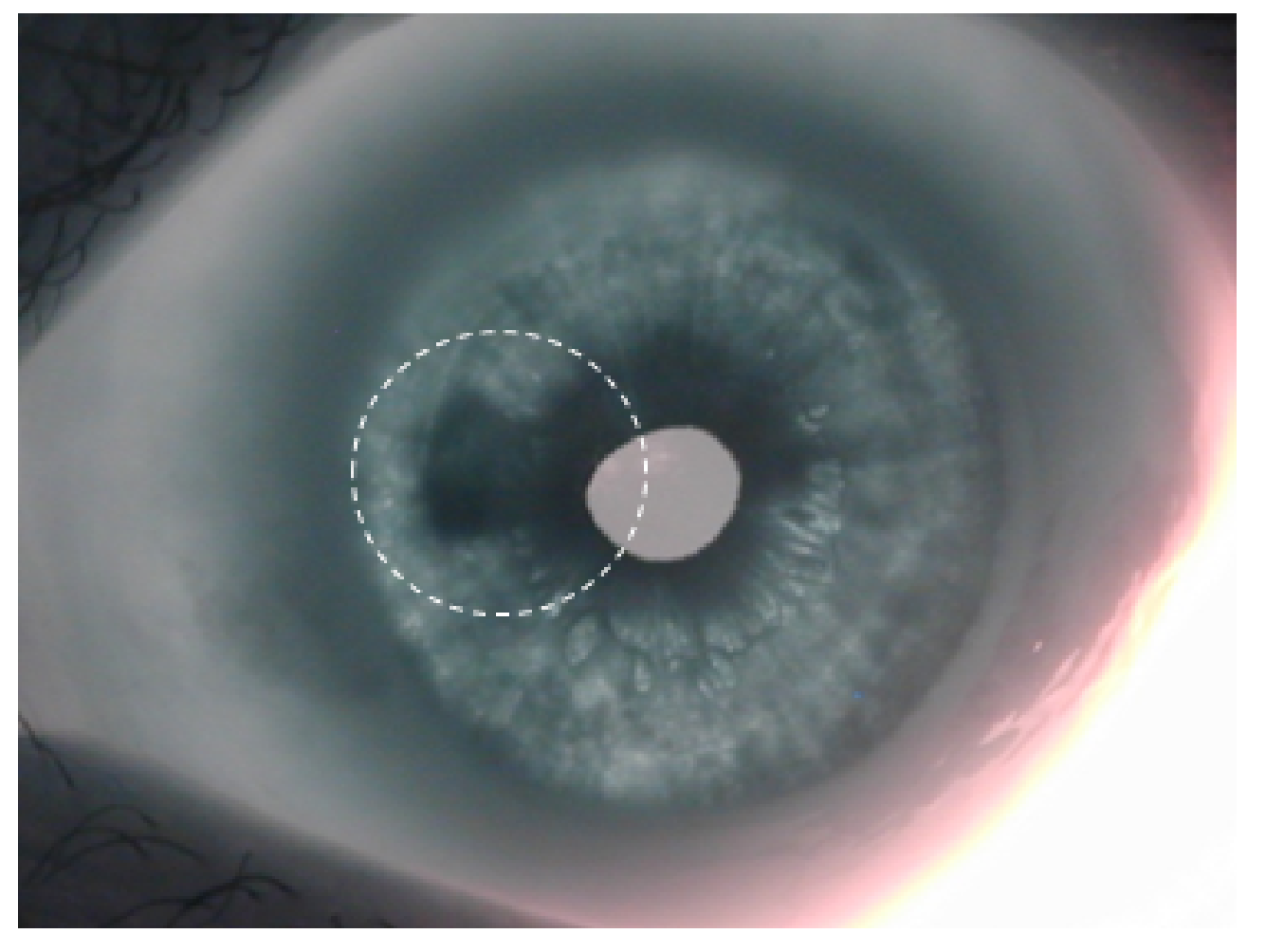




\section{Pupil Shape Measures}
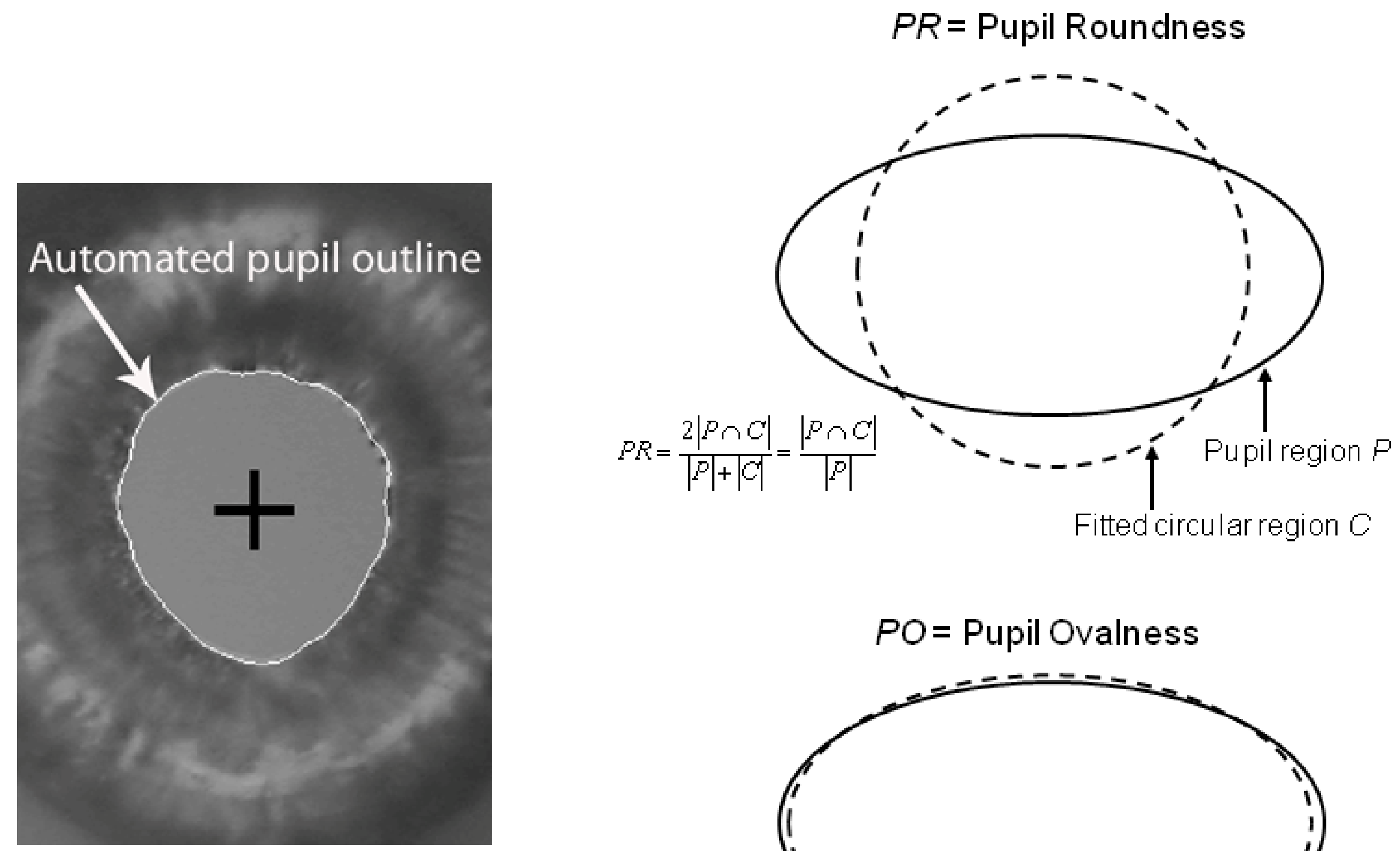

Fitted circular region $C$

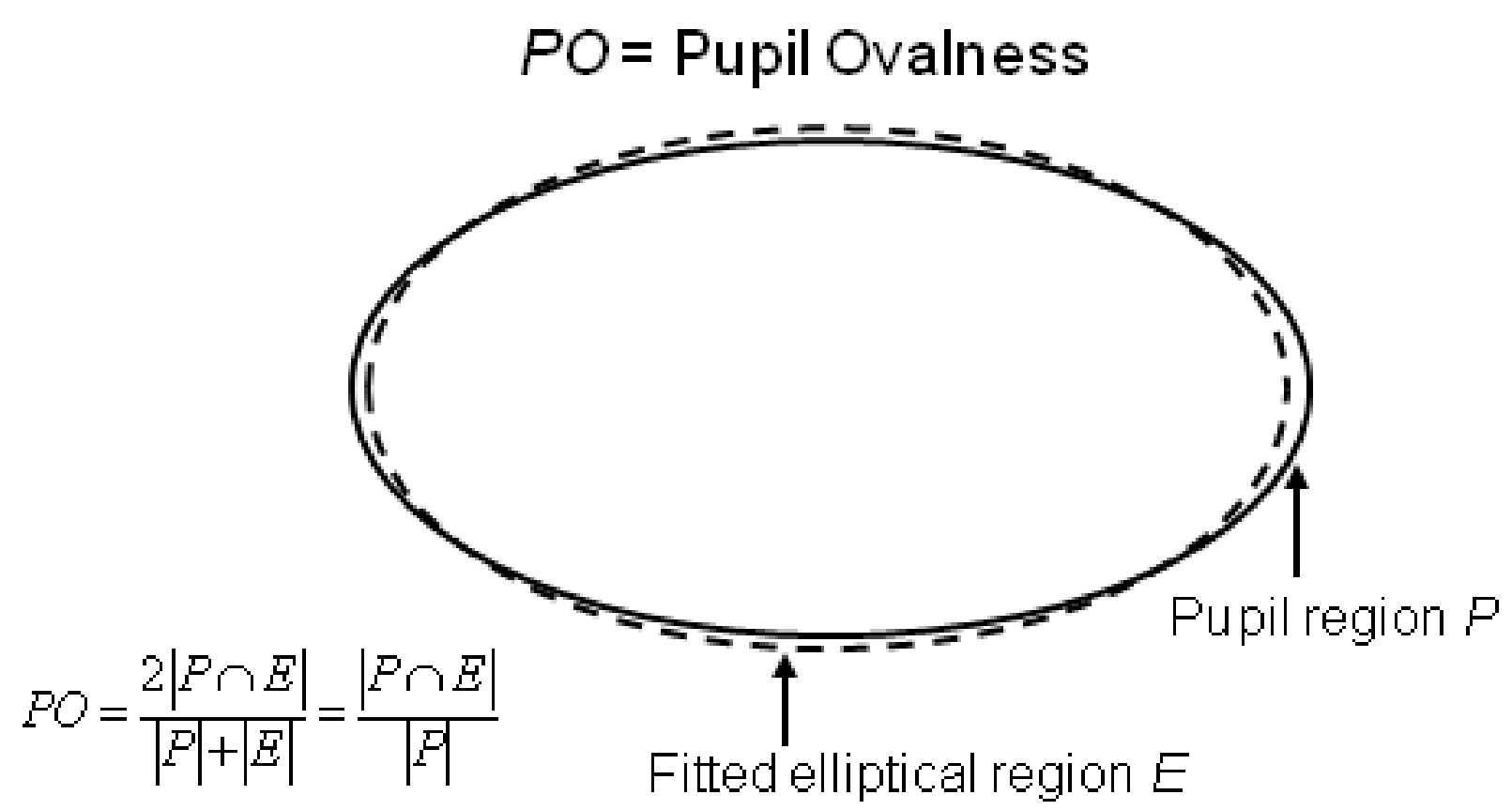




\section{Pupil Eccentricity - PE}

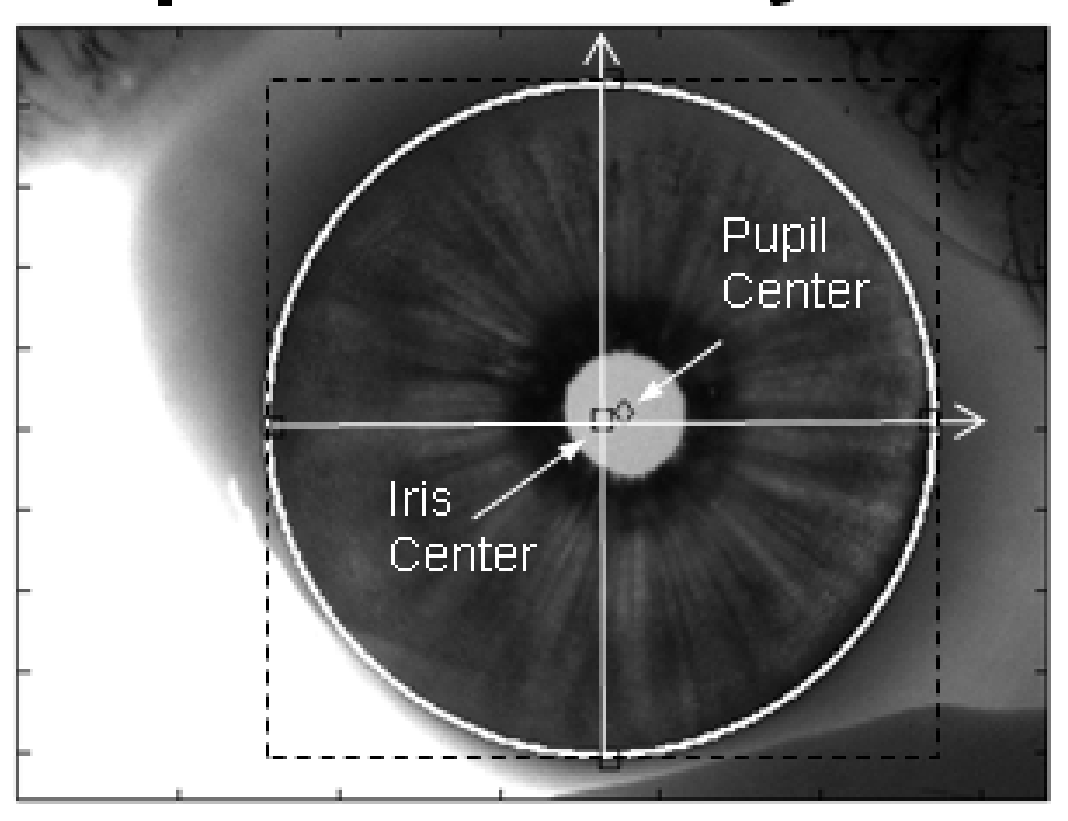

Pupil Size - PS

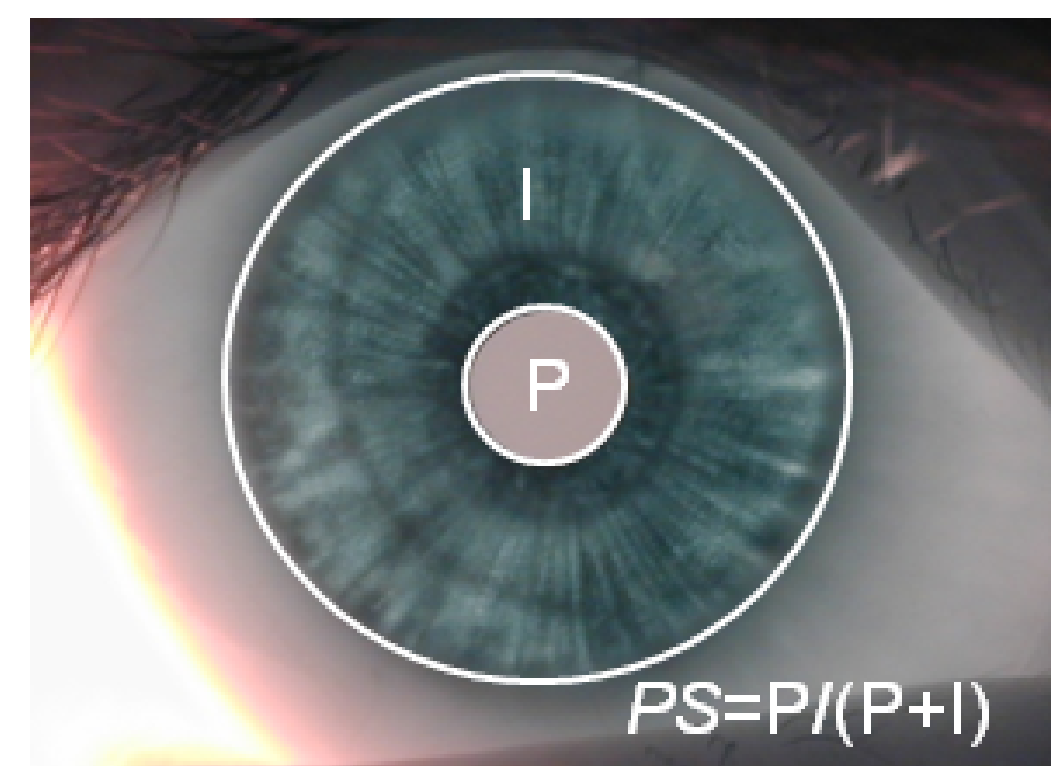




\section{Pupil Circularity Index - PCI}
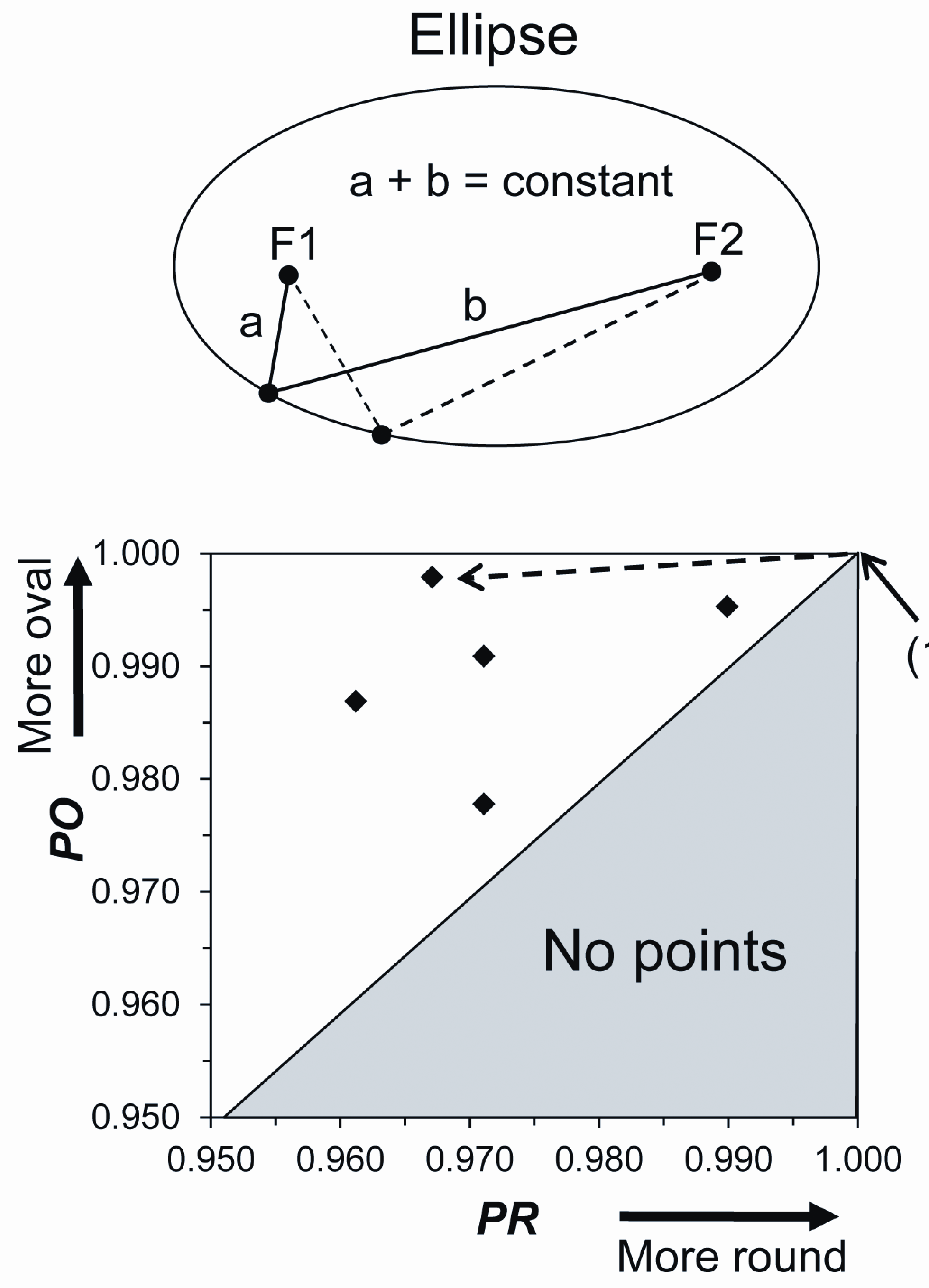
$P R=0.9890$

$P O=0.9989$

$\mathrm{PCl}=0.0111$

Normal

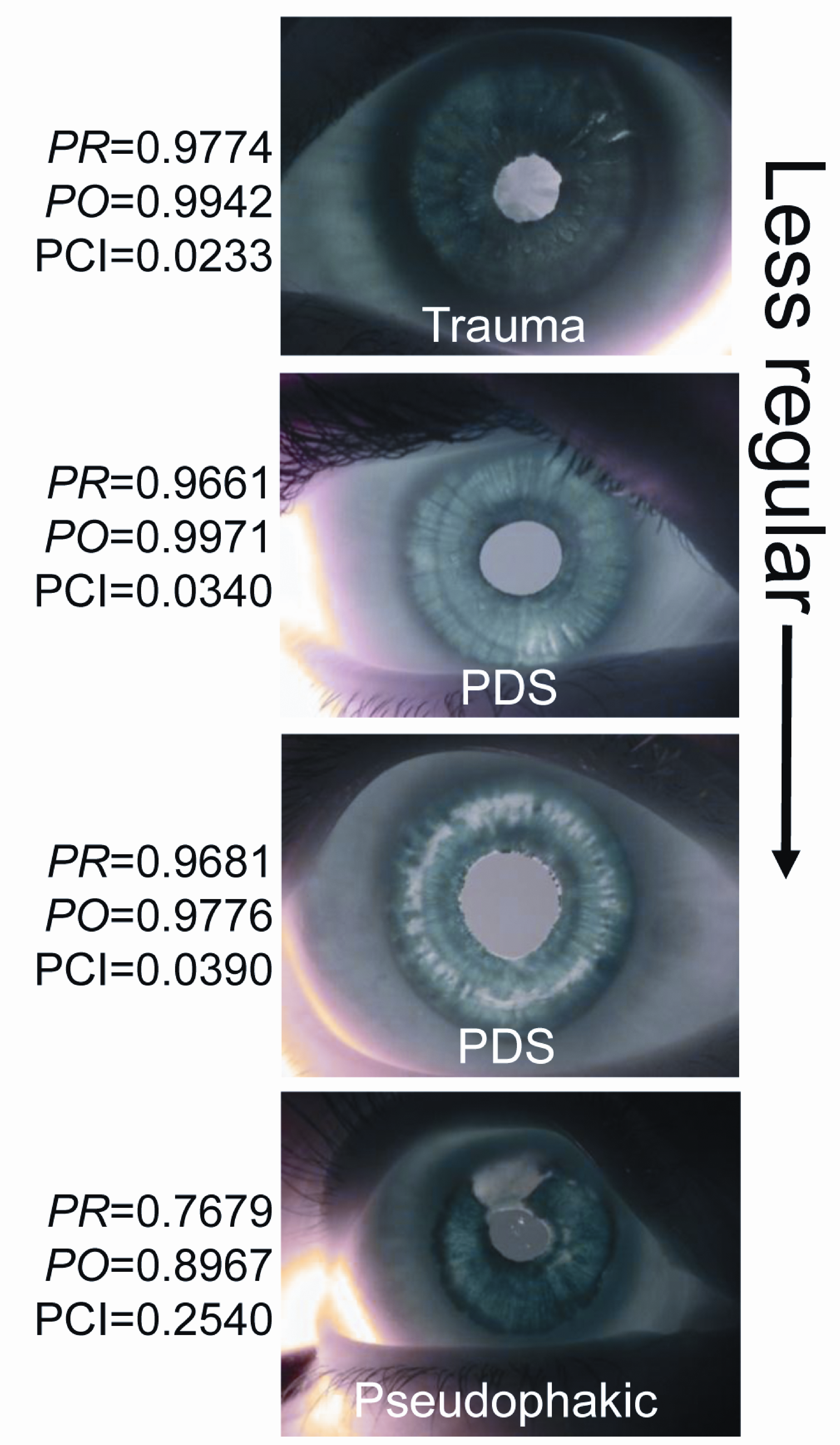



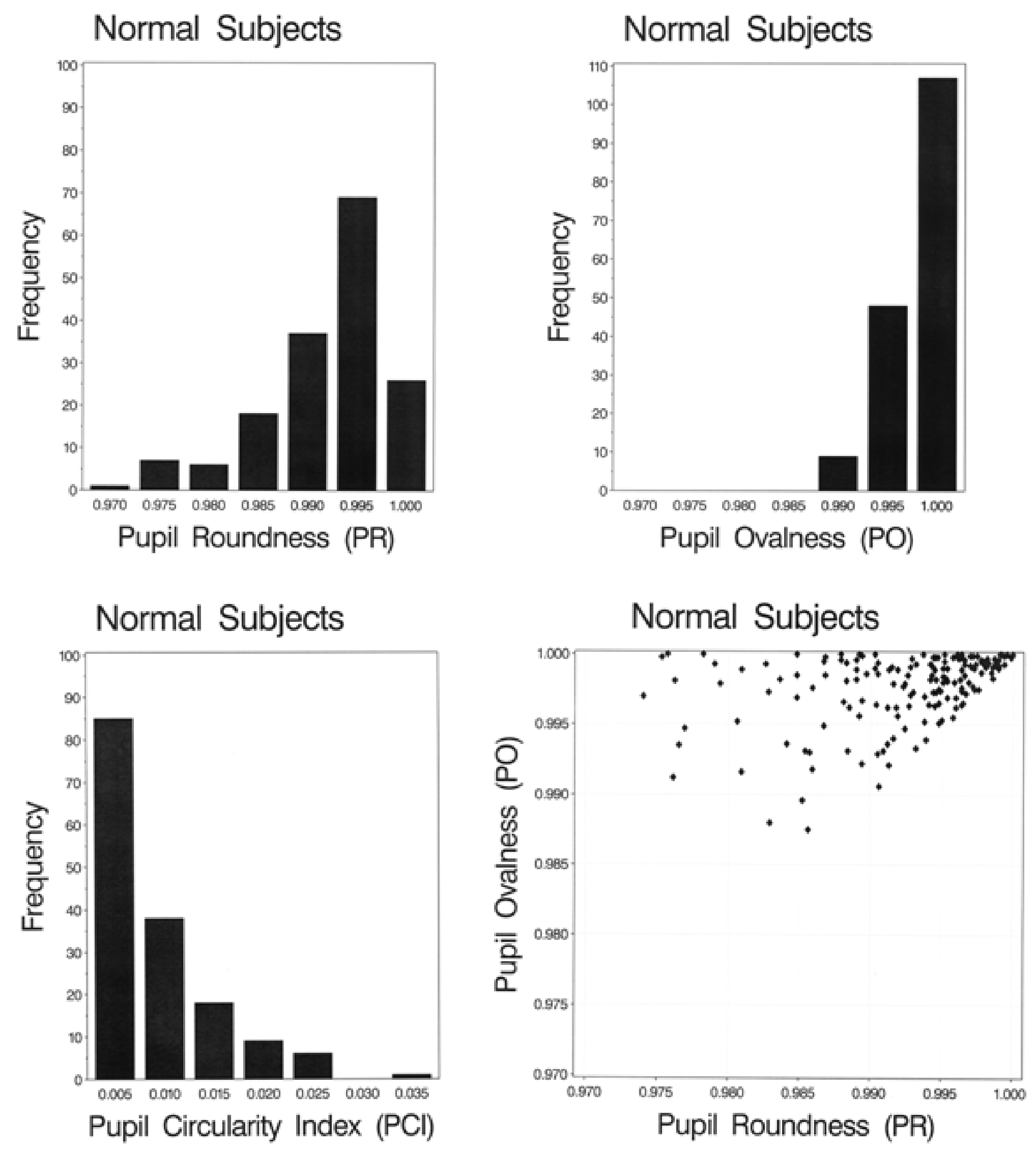

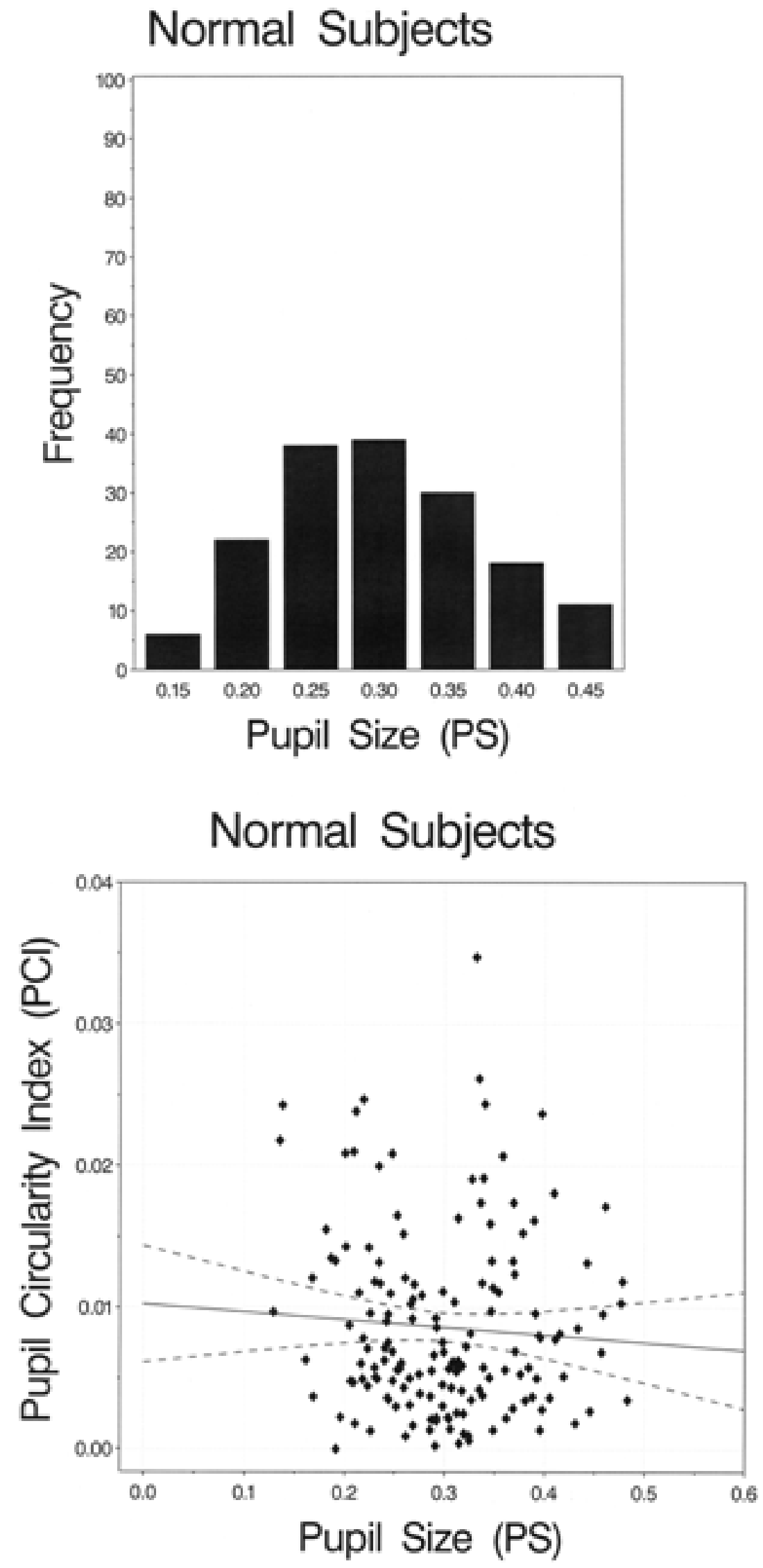
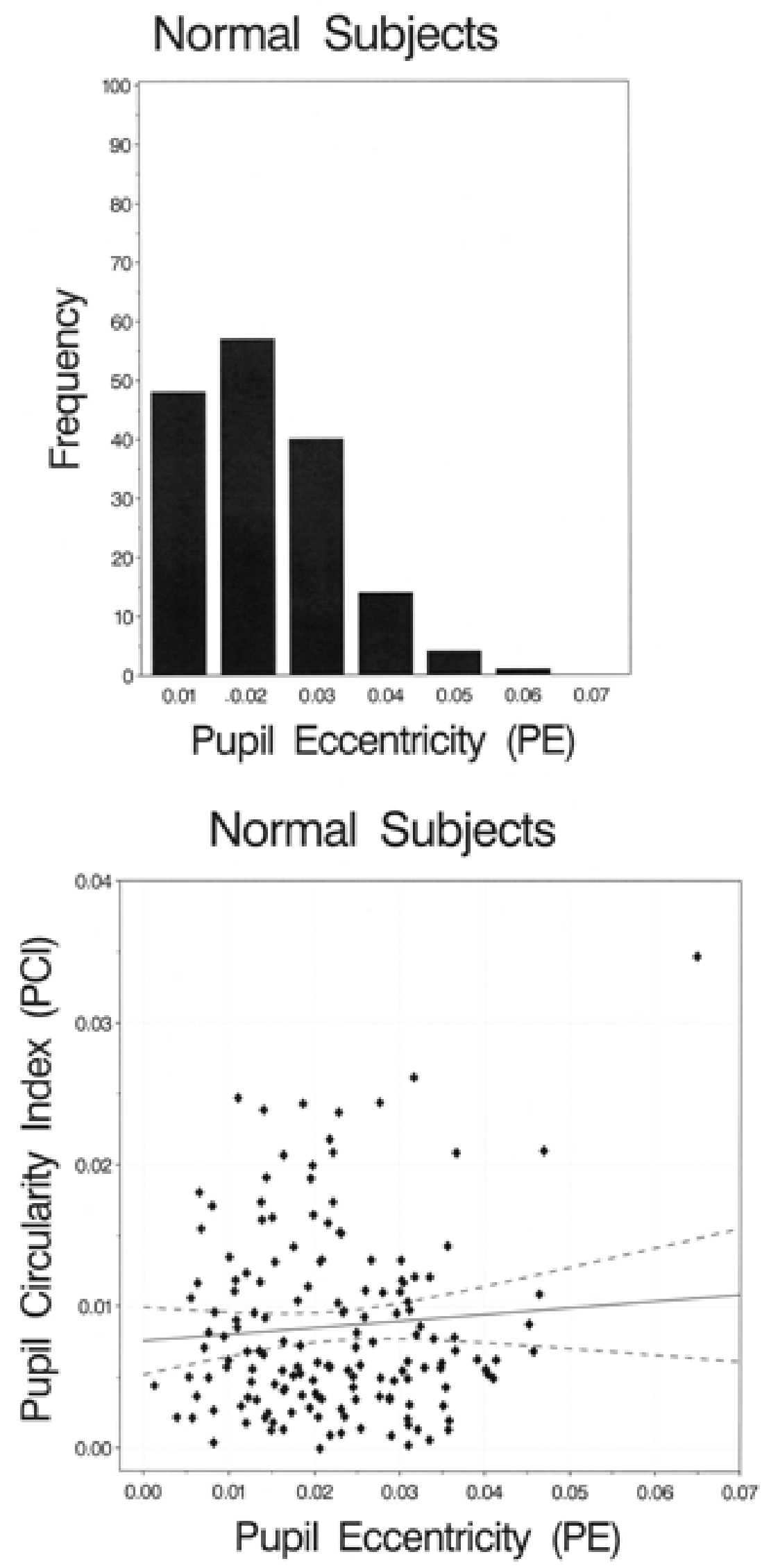


\section{PDS vs. Normal Eyes $-P R$ and $P O$ Measures}
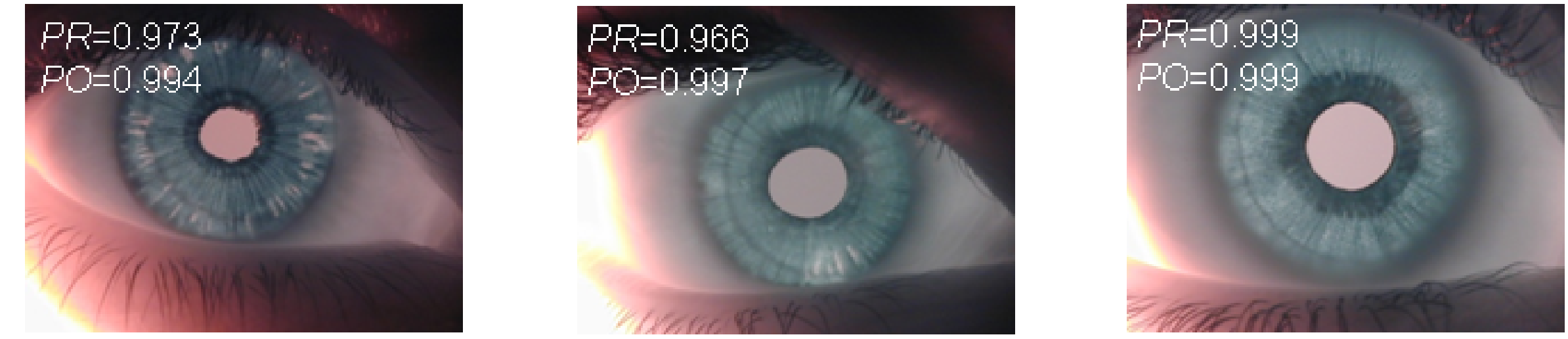

More elliptical than round

More elliptical than round

Both near 1, normal pupil

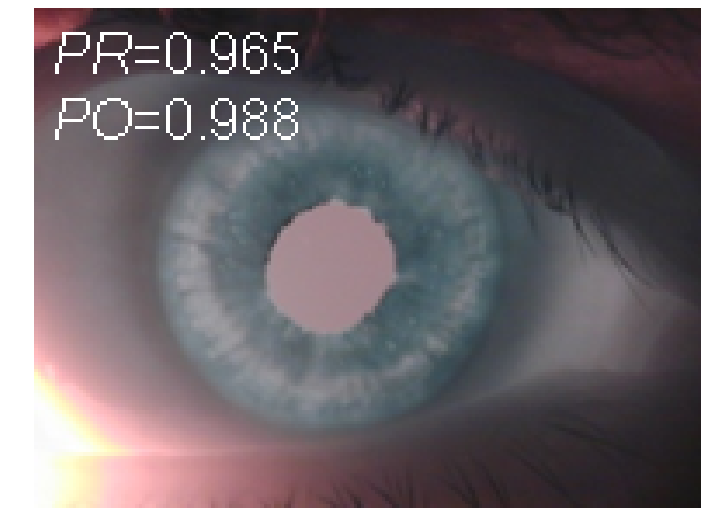

More elliptical than round

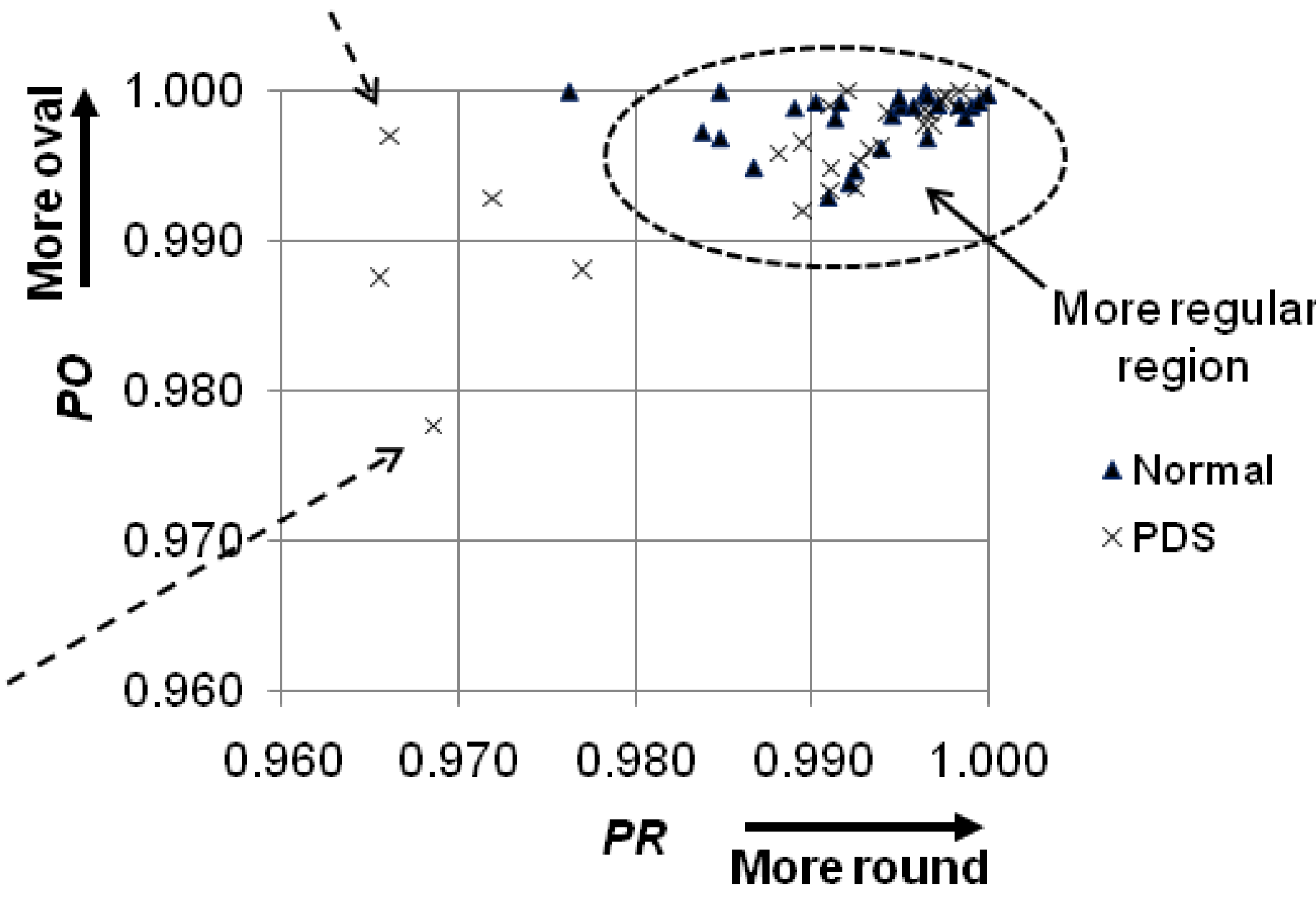

Not round, not elliptical 